Article

\title{
Surface Sizing Treated MWCNTs and Its Effect on the Wettability, Interfacial Interaction and Flexural Properties of MWCNT/Epoxy Nanocomposites
}

\author{
Qingjie Zhang ${ }^{1,2}$, Xinfu Zhao ${ }^{1}$, Gang Sui ${ }^{1, *}$ and Xiaoping Yang ${ }^{1}$ \\ 1 State Key Laboratory of Organic-Inorganic Composites, College of Materials Science and Engineering, \\ Beijing University of Chemical Technology, Beijing 100029, China; qingjie05110@163.com (Q.Z.); \\ zhaoxinfu1990@126.com (X.Z.); yangxp@mail.buct.edu.cn (X.Y.) \\ 2 Department of Chemical Engineering, Tsinghua University, Beijing 100084, China \\ * Correspondence: suigang@mail.buct.edu.cn; Tel.: +86-10-6442-7698
}

Received: 23 July 2018; Accepted: 28 August 2018; Published: 31 August 2018

\begin{abstract}
A surface-sizing technique was offered to take full advantage of multi-walled carbon nanotubes (MWCNTs) and epoxy resins. Two surface-sizing treated MWCNTs were obtained through a ball-milling treatment of amino-functionalized MWCNTs $\left(\right.$ MWCNT- $\left.\mathrm{NH}_{2}\right)$ with $n$-butyl glycidylether (BuGE) and benzyl glycidylether (BeGE). These were referred to as MWCNT-BuGE and MWCNT-BeGE. The results indicated that the surface sizing effectively enhanced wettability, dispersibility of MWCNTs in the epoxy resin. These ameliorating effects, along with improved interfacial interaction between MWCNT-BeGE containing benzene rings and the epoxy matrix, which can offer a more efficient local load-transfer from matrix to MWCNTs, as observed by a higher G-band shift in Raman spectrum under bending loads than that of MWCNT-BuGE reinforced ones. Correspondingly, MWCNT-BeGE/epoxy nanocomposites exhibited increasing flexural strength and modulus of $22.9 \%$ and $37.8 \%$ respectively compared with the neat epoxy, and $7.3 \%$ and $7.7 \%$ respectively compared with MWCNT-BuGE/epoxy nanocomposites with the same MWCNT content.
\end{abstract}

Keywords: nanocomposites; epoxy; MWCNTs; surface sizing; interfacial interaction

\section{Introduction}

Epoxy resin has been widely used as the polymer matrix of high performance composites in many engineering fields due to its three-dimensional cross-linked thermoset structures with outstanding mechanical and bonding properties [1-3]. Since the performance requirements of advanced composite materials have been continuously increased in some special industrial applications, such as aviation and aerospace industry, the mechanical properties of epoxy resin also need to be further improved. In addition to changing the chemical structure of the resin matrix, nano-enhancement is also an important technical mean to improve mechanical performances through the incorporation of nano-scale additives [4,5].

Among nano-fillers, carbon nanotubes (CNTs) exhibited high aspect ratios, low density and excellent strength and stiffness, making them excellent fillers for epoxy resins [6-9]. However, reinforcing effect of pristine CNTs on epoxy matrix was often limited by the strong van der Waals interaction and naturally high crystallinity, resulting in their agglomeration and weak interfacial interactions with the resin matrix [10]. Previous researchers often used hydroxy, carboxylic, amino, epoxy and silane functionalization, et al., to enhance the wettability, dispersibility, and surface reactivity of CNTs in a resin matrix [11-17].

Because amino groups can provide strong interactions with epoxy groups via nucleophilic ring-opening, by far, amino functionalization has been known as the most effective way of tackling 
interfacial interaction of CNTs in epoxy composites [18-24]. Khare et al. [22] proved that amido-amine functionalized CNTs facilitated the transfer of mechanical load across the matrix-filler interface, resulting in a $~ 50 \%$ improvement in the Young's modulus compared with the neat cross-linked epoxy by the use of molecular dynamic (MD) simulation. Cha et al. [23] found that melamine functionalized CNT/epoxy nanocomposites exhibited enhancements of Young's modulus by $64 \%$ and ultimate tensile strength by $22 \%$ compared with neat epoxy samples, due to covalent bonds with surface groups in the epoxy matrix via amino groups on melamine. Lavorgna et al. [24] found that silica nanoparticles and 3-amminopropryltriethoxy silane (APTES) functionalized CNTs acted synergistically to improve the storage modulus of nanocomposite of about $25 \%$ in the glassy region and $280 \%$ in the rubbery region compared with neat epoxy.

However, the solid CNTs still easily flocculated into bundles and agglomerated in the liquid resin matrix, due to a solid-liquid phase shift at the interface between CNTs and the matrix during the mixing process, resulting in a lower enhancement effect of the $\mathrm{CNT}-\mathrm{NH}_{2}$ [23,25]. In addition, though traditional epoxy functionalized CNTs can overcome the problem of phase shift, their drawbacks are obvious, as follows: the functionalization method is complicated and non-ideal for large scale applications; some catalysts are introduced into the CNT preparation, which are difficult to remove in further applications [26].

The surface of commercial carbon fibers is often covered with a reactive sizing layer, which can prevent the fibers from damage through the manufacture process, and improve the interfacial wettability and adhesion between fibers and the resin matrix [27]. As one-dimensional materials, CNTs with large aspect ratios can also be treated using a surface sizing layer. However, so far, no studies have been reported in the literature for such a surface sizing technique and its influence on the wettability and dispersibility of CNTs in the epoxy resin, as well as interfacial interaction and mechanical reinforcement of the resulting CNT/epoxy nanocomposites.

In this present study, a surface-sizing processing was proposed to facilitate the preparation of multi-walled carbon nanotube (MWCNT) reinforced epoxy nanocomposites. Two surface sizing treated MWCNTs were obtained through a ball-milling treatment of amino functionalized $\mathrm{MWCNT}^{-\mathrm{NH}_{2}}$ with $n$-butyl glycidylether (BuGE) and benzyl glycidylether (BeGE). These were referred to as MWCNT-BuGE and MWCNT-BeGE. The effects of surface sizing on the wettability and dispersion of MWCNTs in epoxy matrix were determined and compared with control samples. Furthermore, Raman spectroscopy and MD simulation were used to study the interfacial interaction between MWCNTs and the resin matrix. Fractography and flexural properties of the resulting nanocomposites were also discussed with reference to this observation. The surface sizing technique mentioned in this study shows the potential industrial application prospect use to obtain high performance of MWCNT/epoxy nanocomposites.

\section{Materials and Methods}

Diglycidyl ether of bisphenol A (DGEBA, epoxy value, 0.51) and the hardner 4,4'-diaminodiphenyl methane (DDM) were purchased from Tianjin Synthetic Material Research Institute (Tianjin, China). Epoxy diluents, n-butyl glycidylether (BuGE) and benzyl glycidylether (BeGE), were purchased from Aldrich chemical Co. (Milwaukee, WI, USA) as reactive mono-functional epoxy compounds. The simulated molecular structures of raw materials used in this study are shown in Figure 1. The MWCNT-NH 2 (length, 1-5 $\mu \mathrm{m}$; diameter, 10-20 nm) was synthesized through amidation of commercial carboxylated MWCNTs (purity, 95\%; diameter, 10-20 nm, Chengdu Organic Chemical Co., Chengdu, China) with ethanediamine. 


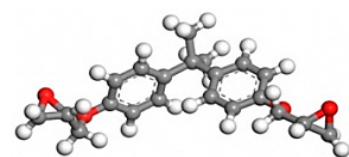

(a)

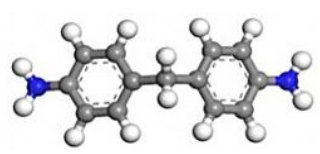

(b)

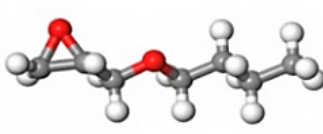

(c)

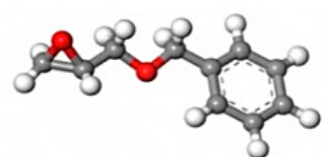

(d)

Figure 1. Simulated molecular structures employed in the molecular dynamic (MD) simulation: (a) diglycidyl ether of bisphenol A (DGEBA), (b) 4,4'-diaminodiphenyl methane (DDM), (c) n-butyl glycidylether (BuGE) and (d) benzyl glycidylether (BeGE), where carbon is shown in gray, oxygen in red, nitrogen in blue and hydrogen in white.

Two kinds of surface sizing treated MWCNTs were obtained by ball-milling $(200 \mathrm{r} / \mathrm{min}, 4 \mathrm{~h})$ MWCNT-NH $\mathrm{H}_{2}$ and epoxy diluents BuGE and BeGE with a mass ratio of 1:2, and then let stand for $72 \mathrm{~h}$ at room temperature. After processing, the solid-liquid weight ratio of these surface sizing treated MWCNTs decreased to 1:1.5, which can be used as nano-fillers for the selected epoxy resin system. Besides, some surface sizing treated MWCNTs were rinsed for five times by using acetone to remove the adsorbed BuGE and BeGE, respectively, and then dried in an oven for later surface characterization. Because each amino group on the surface of MWCNT- $\mathrm{NH}_{2}$ had three reactive hydrogen atoms, ideally, there were three grafted molecule of diluents. The reaction mechanism of surface sizing treated MWCNTs is illustrated in Figure 2. MWCNT-NH$H_{2}$, MWCNT-BuGE and MWCNT-BeGE $(2 \mathrm{mg})$ were dispersed in ethanol $(10 \mathrm{~mL})$ with ultrasonication for $30 \mathrm{~min}$, respectively, and then MWCNT films were obtained by vacuum filtration of MWCNT dispersions via the cellulose filter with a pore size of $0.2 \mu \mathrm{m}$. The resulting MWCNT films were used in later wettability examinations. The 0.5 wt. $\%$ MWCNT-NH $2,1.25$ wt.\% MWCNT-BuGE and 1.25 wt. $\%$ MWCNT-BeGE (the contents of solid MWCNTs was $0.5 \mathrm{wt} . \%$ ) were dispersed in DGEBA epoxy resin by mechanical stirring at room temperature for $10 \mathrm{~h}$, respectively. After this, curing agents (mass ratio, DGEBA:DDM = 100:25) were added to the MWCNT/epoxy system, and the homogeneous mixture was degassed for $30 \mathrm{~min}$ at $80^{\circ} \mathrm{C}$ under vacuum before curing. Then the resin systems were poured into a steel mold, and cured at $90^{\circ} \mathrm{C}$ for $1 \mathrm{~h}, 130^{\circ} \mathrm{C}$ for $2 \mathrm{~h}$, and $180^{\circ} \mathrm{C}$ for $2 \mathrm{~h}$ in an oven.

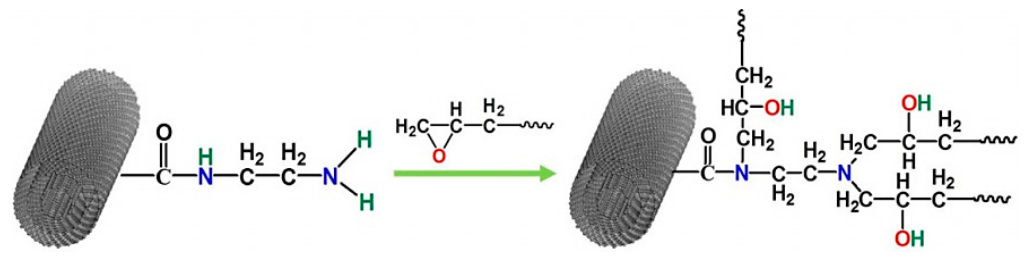

Figure 2. Reaction mechanism of surface sizing treated multi-walled carbon nanotubes (MWCNTs).

The MD simulation of interfacial interaction between the surface sizing treated MWCNTs and the resin matrix was performed using the Forcite module of Materials Studio (6.0, Accelrys Inc., San Diego, CA, USA). The condensed phase optimized molecular potential for atomistic simulation studies (COMPASS) force field was employed to analyze the intramolecular and intermolecular interactions with a constant number of molecules, constant volume, and constant temperature (NVT) ensemble at $300 \mathrm{~K}$ with no applied pressure [9]. A time step of $1 \mathrm{fs}$, an equilibration time of $0.5 \mathrm{~ns}$, and a production run time of $30 \mathrm{ps}$ were used in this simulation. The covalent interaction energy $\left(E_{\text {inter }}\right)$ between resin matrix and surface-sizing MWCNTs was calculated according to the Equation (1) [9]:

$$
E_{\text {inter }}=E_{\text {total }}-\left(E_{C N T s}+E_{\text {resin matrix }}\right)
$$

where $E_{\text {total }}$ was the total potential energy between the surface-sizing MWCNTs and resin matrix pair via covalent interaction, and $E_{C N T s}$ was the potential energy of surface-sizing MWCNTs when the resin 
matrix was put at infinite distance, $E_{\text {resin matrix }}$ can be defined as the potential energy of resin matrix when the surface-sizing MWCNTs were put at infinite distance.

The MWCNT-NH 2 , MWCNT-BuGE and MWCNT-BeGE materials were analyzed and determined through high resolution transmission electron microscopy (HRTEM, Tecnai G2 F30 S, FEI Co., Hillsboro, OR, USA), transmission electron microscopy (TEM, JEM 3010, JEOL, Tokyo, Japan), Fourier-transform infrared spectroscopy (FT-IR, Nicolet 670, Nicolai Instruments, Madison, WI, USA), X-ray photoelectron spectroscopy (XPS, PHI-5300, Ulvac-Phi Inc., Chigasaki, Japan), thermogravimetric analysis (TGA, TA Q50, TA Instruments, New Castle, DE, USA) and Raman spectroscopy (TY-HR 800, HORIBA, Paris, France). In the thermogravimetric analysis, the heating rate was $10^{\circ} \mathrm{C} / \mathrm{min}$ from room temperature to $800{ }^{\circ} \mathrm{C}$ under $\mathrm{N}_{2}$ (FR $=40 \mathrm{~mL} / \mathrm{min}$ ). The Raman spectroscopy was obtained by using a near-infrared laser line (wavelength of $785 \mathrm{~nm}$ ). Micro-mechanical behaviors of MWCNTs in resin matrix under bending loads were characterized by measuring a total of 676 points per image over a scan width and height of $5 \mu \mathrm{m} \times 5 \mu \mathrm{m}$. The contact angles of DGEBA on the MWCNT films were measured to investigate the changes in wettability on a goniometer (OCA20, DataPhysics, Stuttgart, Germany) at room temperature. The image analyzing software (Image J, 1.48, National Institutes of Health, Bethesda, MD, USA) was used to calculate the contact angle. Three key points were found first: left-end point, right-end point and vertex of the droplet. Then, the height $(h)$ and width $(2 r)$ of droplet and the solid-liquid contact angle $(\theta)$ of the droplet can be obtained from the defined coordinates of these points. The dispersion performance of the MWCNTs in the resin matrix was observed using fractured, cured composite samples on a scanning electron microscope (SEM, JSM 7401F, JEOL, Tokyo, Japan) under $20 \mathrm{kV}$ accelerating voltage. According to the standard test method ASTM D790, flexural tests of epoxy composites were performed on a material testing machine (WDS-10, Beijing Guance Jingdian Instrument Inc., Beijing, China) at the speed of $2 \mathrm{~mm} / \mathrm{min}$. Each data point was obtained from at least ten samples.

\section{Results and Discussion}

\subsection{Surface Characterization of MWCNTs}

Figure $3 \mathrm{a}-\mathrm{c}$ showed digital photographs and the corresponding HRTEM images (inset) of MWCNT-NH ${ }_{2}$, MWCNT-BuGE and MWCNT-BeGE. As shown, MWCNT-NH $\mathrm{N}_{2}$ was solid powders, while MWCNT-BuGE and MWCNT-BeGE became semisolid particles after the surface sizing treatment. Compared with MWCNT-NH $\mathrm{N}_{2}$, the structural integrity of MWCNT-BuGE and MWCNT-BeGE maintained well, indicating negligible damages to graphite sheet layer structure during surface sizing treatment (Figure 3a-c, inset). At the same time, the surfaces of both $\mathrm{MWCNT}-\mathrm{NH}_{2}$ and surface sizing treated MWCNTs were covered by amorphous materials, which can be assigned to the chemical groups [28]. However, the difference between covering layers of these MWCNT samples did not distinguish well, due to the low molecular weight of chemical compounds.

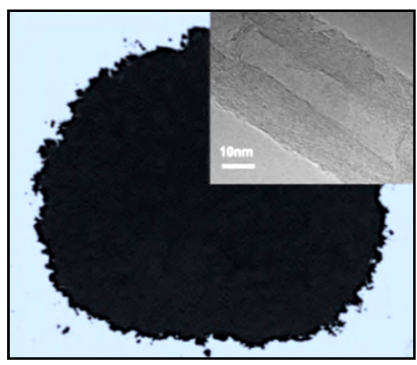

(a)

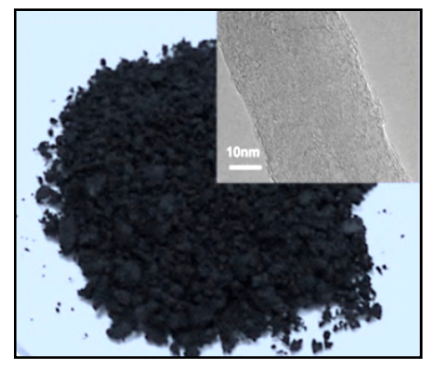

(b)

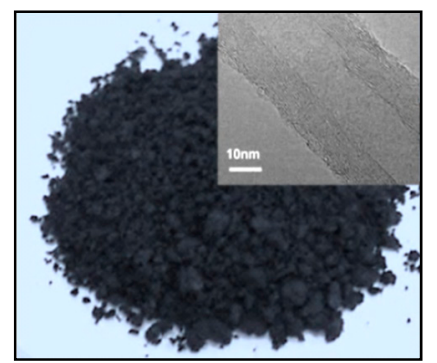

(c)

Figure 3. Cont. 


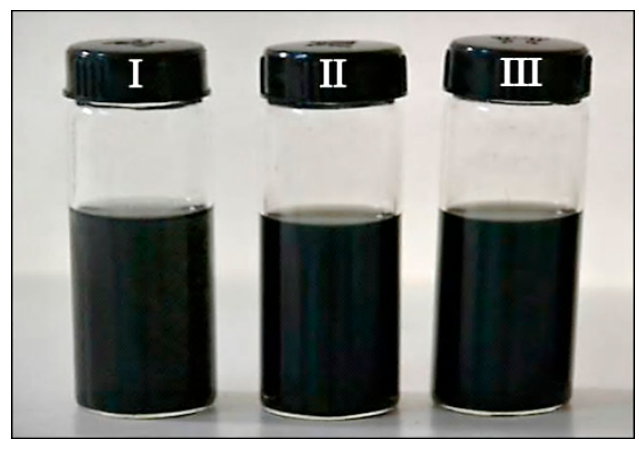

(d)

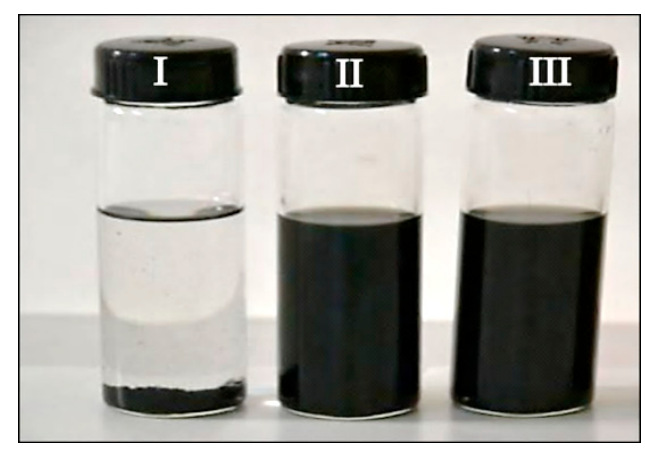

(e)

Figure 3. Optical images and high resolution transmission electron microscopy (HRTEM) (inset)

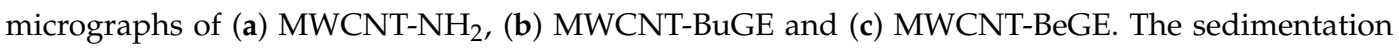
behavior of (I) MWCNT-NH 2 , (II) MWCNT-BuGE and (III) MWCNT-BeGE in the ethanol solution after standing for (d) $1 \mathrm{~h}$ and (e) $24 \mathrm{~h}$ under $25^{\circ} \mathrm{C}$.

Observing the dispersion stability of CNTs in an organic solvent has been considered a semi-qualitative method to judge success or failure of the surface modification of CNTs [29]. $1 \mathrm{mg} / \mathrm{mL}$ of MWCNT-NH $\mathrm{N}_{2}, \mathrm{MWCNT}-\mathrm{BuGE}$ and MWCNT-BeGE in absolute ethanol were ultrasonicated for $10 \mathrm{~min}$, respectively, and their optical images were taken after standing for $1 \mathrm{~h}$ (Figure 3d) and $24 \mathrm{~h}$ (Figure 3e). MWCNT-NH ${ }_{2}$ was precipitated gradually, while MWCNT-BuGE and MWCNT-BeGE still retained dispersion stability after standing for $24 \mathrm{~h}$, because the sizing processing changed the surface polarity of MWCNTs, preventing MWCNTs from re-aggregation.

Figure 4 shows TEM micrographs of MWCNT-NH ${ }_{2}$, MWCNT-BuGE and MWCNT-BeGE that further illustrate their dispersion states in ethanol as solvent. Small MWCNT agglomerates can be clearly seen in the sample of $\mathrm{MWCNT}-\mathrm{NH}_{2}$ (Figure 4a). After the surface sizing process, the length of MWCNT-BuGE (Figure 4b) and MWCNT-BeGE (Figure 4c) was reduced from $~ 1-5 \mu \mathrm{m}$ to $\sim 0.5-1 \mu \mathrm{m}$, and no MWCNT agglomerates were observed. The surface sizing treatment led to the efficient debundling and dispersion of the MWCNTs in organic solvents.

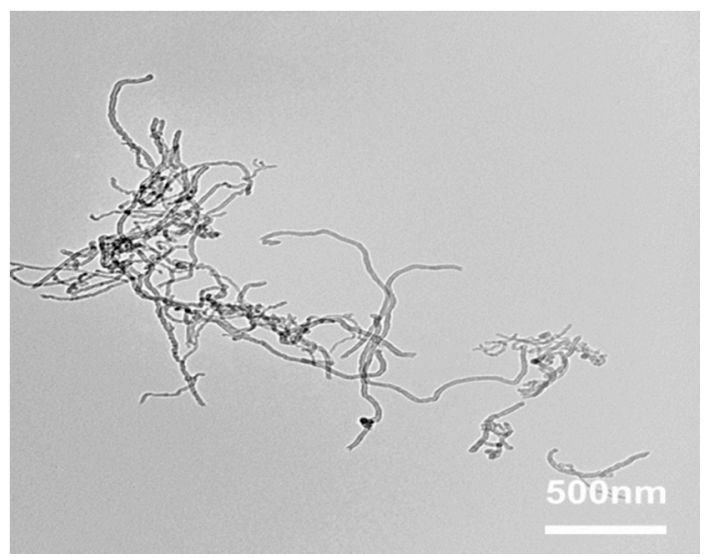

(a)

Figure 4. Cont. 


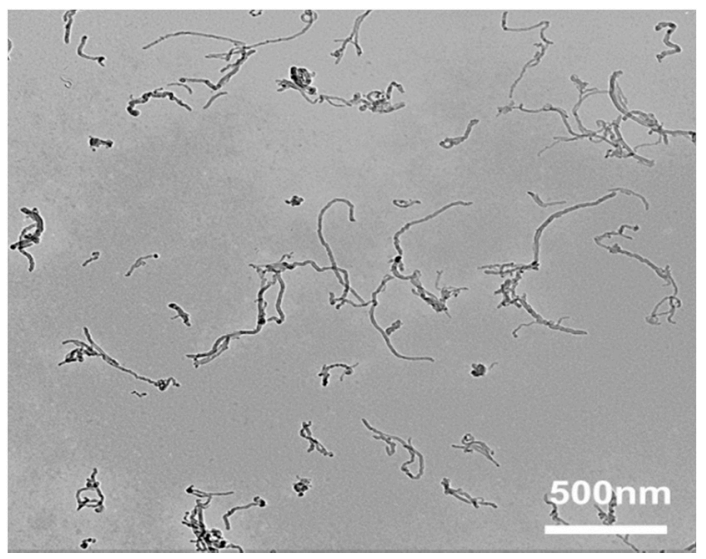

(b)

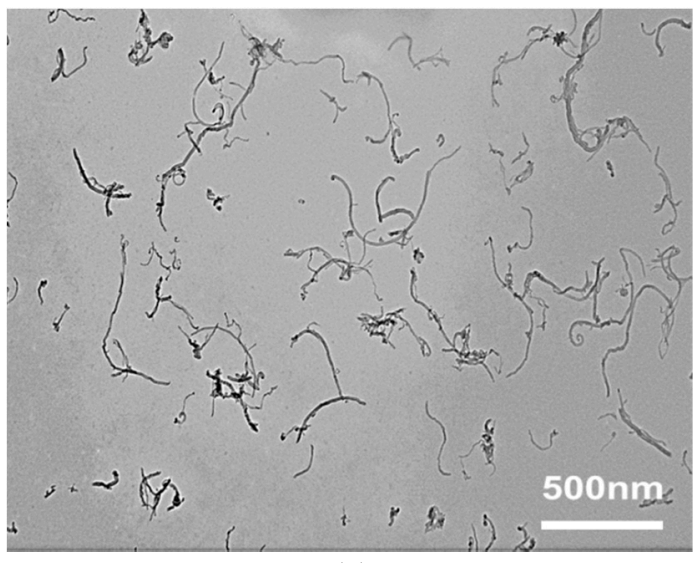

(c)

Figure 4. Transmission electron microscopy (TEM) photographs of (a) $\mathrm{MWCNT}^{-\mathrm{NH}_{2}}$, (b) MWCNTBuGE and (c) MWCNT-BeGE.

Figure 5 shows the FT-IR spectra of MWCNT-NH $\mathrm{N}_{2}, \mathrm{MWCNT}-\mathrm{BuGE}$ and MWCNT-BeGE. The $3428 \mathrm{~cm}^{-1}$ peak was originated from the $\mathrm{O}-\mathrm{H}$ stretching vibration of water molecules which were present in the $\mathrm{KBr}$ as well as in carbon nanotubes [30]. The peaks of MWCNT- $\mathrm{NH}_{2}$ at $1630 \mathrm{~cm}^{-1}$ and $1092 \mathrm{~cm}^{-1}$ were ascribed to the stretching vibration of $\mathrm{N}-\mathrm{H}$, and $\mathrm{C}-\mathrm{N}$ deriving from primary amino groups [25], respectively. Peaks at $2850-2926 \mathrm{~cm}^{-1}$ region were characteristics of symmetric and asymmetric stretching vibration of $-\mathrm{CH}_{2}-$ groups, and their intensities were greatly enhanced in MWCNT-BuGE and MWCNT-BeGE materials. The introduction of BuGE and BeGE can be observed from the peak at $1109 \mathrm{~cm}^{-1}$, which was assigned to $\mathrm{C}-\mathrm{O}-\mathrm{C}$ stretching frequencies. Moreover, strong absorption peaks at $739 \mathrm{~cm}^{-1}$ and $696 \mathrm{~cm}^{-1}$ resulting from out of plane bending of the benzene ring were also observed in the MWCNT-BeGE.

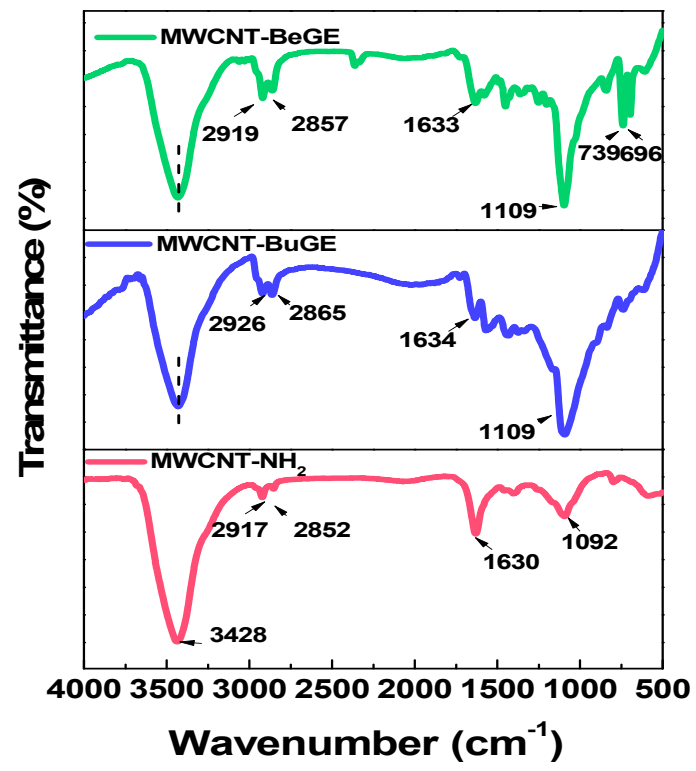

Figure 5. Fourier-transform infrared spectroscopy (FT-IR) spectra of MWCNT-NH $\mathrm{M}_{2}$, MWCNT-BuGE and MWCNT-BeGE.

To distinguish the adsorbed or chemically bonded surface molecules on the surface of MWCNTs, the identification of surface functionalities was performed through calculating the N1s peak area of MWCNT-NH $\mathrm{N}_{2}, \mathrm{MWCNT}-\mathrm{BuGE}$ and MWCNT-BeGE. Figure 6 shows XPS (N1s) curve fitting for three kinds of MWCNTs, and corresponding N1s peak area of each type of MWCNTs was shown in Table 1. 
$\mathrm{N} 1 \mathrm{~s}$ peak positions at $399.87 \mathrm{eV}, 401.03 \mathrm{eV}$ and $402.30 \mathrm{eV}$ were attributed to the chemical bonds $\mathrm{C}-\mathrm{N}-\mathrm{C}$, $\mathrm{C}-\mathrm{NH}_{2}$ and $-\mathrm{NH}-\mathrm{C}=\mathrm{O}[25]$.

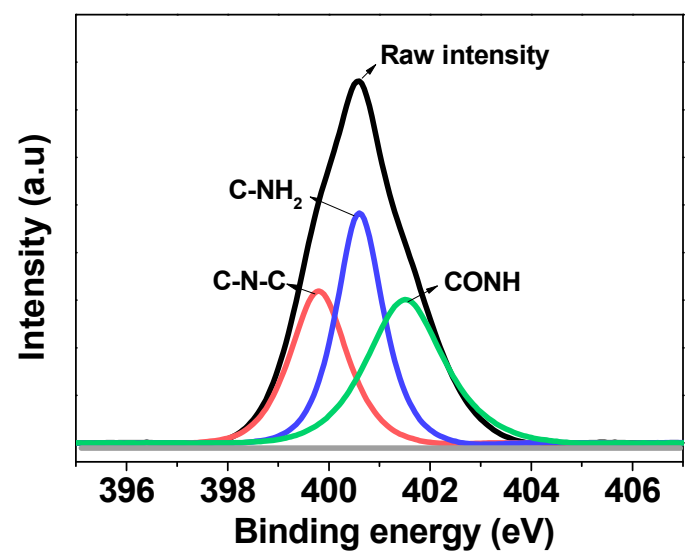

(a)

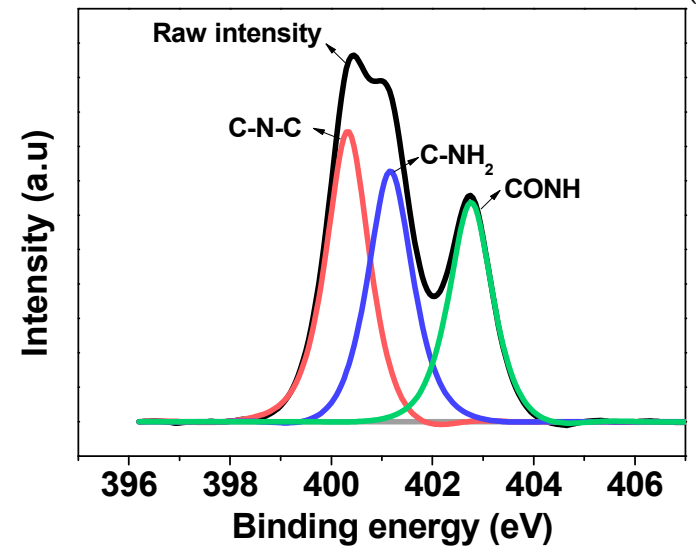

(b)

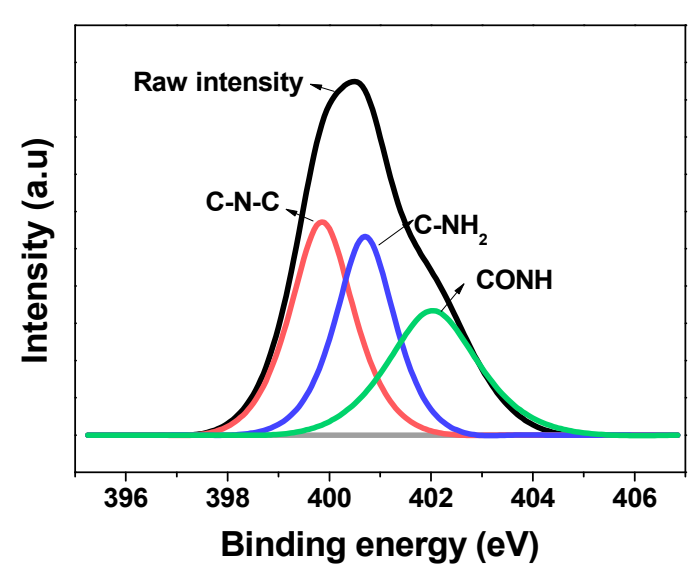

(c)

Figure 6. X-ray photoelectron spectroscopy (XPS) N1s curve fitting peak of (a) MWCNT-NH , $^{\text {(b) }}$ MWCNT-BuGE and (c) MWCNT-BeGE.

Table 1. N1s peak area of MWCNT-NH 2 , MWCNT-BuGE and MWCNT-BeGE.

\begin{tabular}{cccc}
\hline Samples & $\begin{array}{c}\mathrm{C}-\mathbf{N}-\mathrm{C} \\
\mathbf{( \% )}\end{array}$ & $\begin{array}{c}\mathbf{C}-\mathbf{N H}_{\mathbf{2}} \\
\mathbf{( \% )}\end{array}$ & $\begin{array}{c}-\mathbf{N H}-\mathbf{C}=\mathbf{O} \\
\mathbf{( \% )}\end{array}$ \\
\hline MWCNT-NH & 31.4 & 35.0 & 33.6 \\
MWCNT-BuGE & 38.0 & 33.5 & 28.5 \\
MWCNT-BeGE & 36.7 & 31.9 & 31.4 \\
\hline
\end{tabular}

In the samples of the MWCNT-BuGE and MWCNT-BeGE, the peak area of C-N-C bond increased, while the corresponding peak area of $\mathrm{C}-\mathrm{NH}_{2}$ bond decreased compared with the results for the MWCNT- $\mathrm{NH}_{2}$ (Table 1). These results suggested that new $\mathrm{C}-\mathrm{N}-\mathrm{C}$ chemical bonds were formed, which directly validated the chemical reaction between the epoxy diluent and the amino group of the MWCNT-NH $\mathrm{N}_{2}$. The results of XPS analysis demonstrated that BuGE and BeGE have been successfully bonded to the surface of the MWCNT- $\mathrm{NH}_{2}$ through covalent bonds.

Figure 7a shows the TGA analysis for MWCNT-NH ${ }_{2}$, MWCNT-BuGE and MWCNT-BeGE. The weight loss of MWCNT-NH $\mathrm{N}_{2}$ was about $10 \%$ at $800{ }^{\circ} \mathrm{C}$, due to the decomposition of the amino groups. The weight loss of the MWCNT-BuGE and MWCNT-BeGE was $32 \%$ and $28 \%$, respectively. This increase in weight loss was attributed to the grafting of mono-functional epoxy molecules on the surface of MWCNT-NH$H_{2}$. 


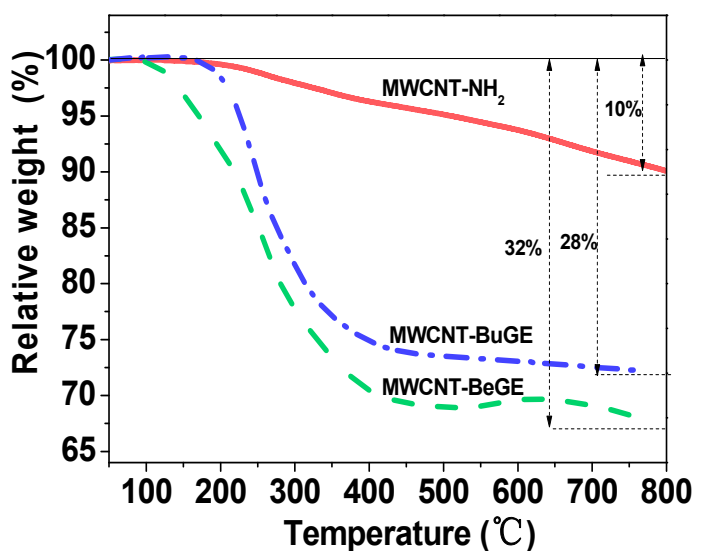

(a)

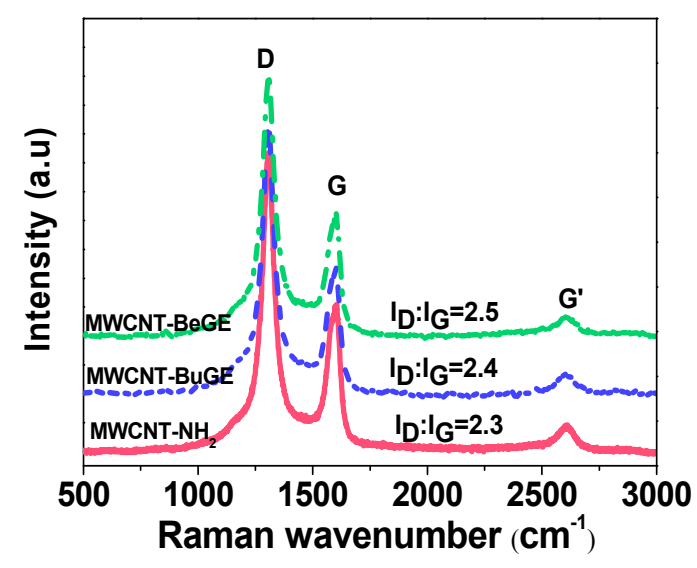

(b)

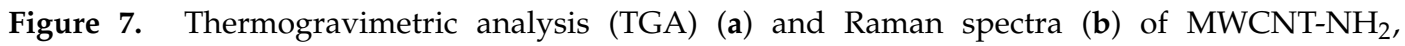
MWCNT-BuGE and MWCNT-BeGE.

In addition, the weight loss of MWCNT-BuGE at $800{ }^{\circ} \mathrm{C}$ was higher than that of MWCNT-BeGE. This difference in weight loss between the MWCNT-BuGE and MWCNT-BeGE was attributed to the increased reactivity of the amino group $\left(\mathrm{NH}_{2}-\left(\mathrm{CH}_{2}\right)_{2}-\mathrm{NH}-\mathrm{CO}-\right)$ in the BuGE and BeGE molecules on the surface of MWCNTs. The ratio (n) of epoxy diluents to amino groups is roughly calculated using the Equation (2) [31]:

$$
n=\frac{\left(X_{e}-X_{a}\right) / M_{e}}{X_{a} / M_{a}}
$$

where $X_{e}$ and $X_{a}$ is the weight loss of the MWCNT surface sizing and MWCNT-NH$H_{2} ; M_{e}$ and $M_{a}$ is the molecular mass of BuGE (or BeGE) and the amino groups. The $n$ of MWCNT-BuGE and MWCNT-BeGE was 1.5 and 1.0, indicating that BuGE reacted easier with the amine groups on the surface of MWCNT-NH $\mathrm{N}_{2}$ than that of BeGE. Moreover, the remaining activated amine groups in the surface sizing still had the ability to participate into the crosslinking network via ring-opening reaction with epoxy groups.

Raman spectroscopy is one of the most important techniques for the analysis of the vibrational modes and the structure of carbon nanotubes [32,33]. Figure $7 \mathrm{~b}$ shows Raman analysis results of the functionalized MWCNTs, where the peak positions at $1311 \mathrm{~cm}^{-1}, 1601 \mathrm{~cm}^{-1}$ and $2608 \mathrm{~cm}^{-1}$ were attributed to the disorder-induced D band (in-plane vibrations of $\mathrm{sp}^{3}$ carbon), the $\mathrm{G}$ band (the crystalline graphitic and in-plane vibrations of $\mathrm{sp}^{2}$ carbon), and the $\mathrm{G}^{\prime}$ band (the second overtone of the D-band) [34]. The relative intensity ratio, $I_{\mathrm{D}} / I_{\mathrm{G}}$, was sensitive to physical and chemical processing of the CNTs, and it was an indication of the degree of amorphous carbon atoms to graphitic carbon atoms on the surface of the CNTs, which reflected the structural integrity of the graphite [33]. The $I_{\mathrm{D}} / I_{\mathrm{G}}$ of MWCNT-BuGE (2.4) and MWCNT-BeGE (2.5) was a little higher than that of the MWCNT-NH 2 (2.3), suggesting that the surface sizing treatment had little negative effect on the structural integrity of the graphite, consistent with the observation of HRTEM analysis (Figure 3a-c).

\subsection{Interfacial Analysis of MWCNT/Epoxy Nanocomposite}

For inorganic filler-reinforced polymeric composites, a good wettability is a primary prerequisite to rapidly construct interfaces between the fillers and the resin matrix [35,36]. Figure 8 shows contact angles changing with time of DGEBA on the MWCNT film at room temperature, which is used to evaluate the effect of surface sizing treatment on the MWCNT wettability with the resin matrix. As shown, the initial contact angle of DGEBA on the MWCNT-NH${ }_{2}$ film was $129^{\circ}$. After the surface sizing treatment, the initial contact angles of DGEBA on the MWCNT-BuGE and MWCNT-BeGE films were down to around $110^{\circ}$, because the polarity of alkyl chain was smaller than that of the amino group. The liquid DGEBA spread over the MWCNT film due to the surface tension effect and the interfacial 
energy of the droplet, resulting in the decrease of contact angles with time. Dynamic contact angles of DGEBA on the MWCNT-BuGE and MWCNT-BeGE film were similar, but always smaller than that on the MWCNT-NH 2 film. The results indicated that a better wettability with the epoxy resin can be obtained via surface-sizing treatment of MWCNT-NH $\mathrm{N}_{2}$.

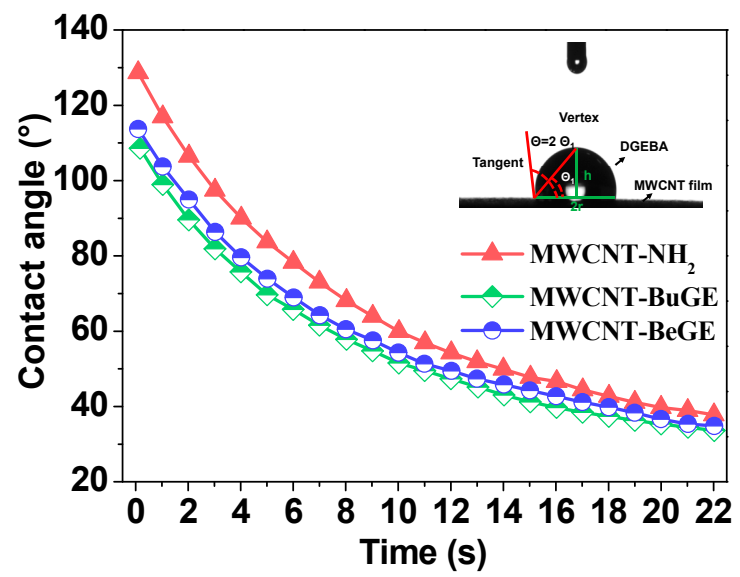

Figure 8. Dynamic contact angle of DGEBA on MWCNT-NH 2, MWCNT-BuGE and MWCNT-BeGE films varies with time at room temperature (Inset image is the contact angle measurement process with side view of DGEBA on the MWCNT film).

An adequate interfacial bonding strength can guarantee efficient load-transfer between the MWCNTs and resin matrix, and promote the comprehensive performance of the final nanocomposites [22,37]. When a strain occurred in a material system under the action of external force, the inter-atomic distances were changed, resulting in some changes of vibration frequency of some normal modes, which would be shown as a slight shift of Raman peak. The Raman G band of a better interfacial interaction between the MWCNTs and the epoxy matrix would shift to a higher wave number when the MWCNTs embedded in the epoxy resin were subjected to the strain [37]. Therefore, Raman G band shift can be used to assess the interfacial interaction between the MWCNTs and epoxy matrix.

Figure 9 shows the $\mathrm{G}$ band intensity distribution over the scanned area of cured DGEBA/DDM nanocomposites reinforced by MWCNT-NH 2 , MWCNT-BuGE and MWCNT-BeGE without or with $1 \%$ bending load at room temperature. There was no significant difference in the $G$ band frequency ( 1582.0) among the MWCNT-NH, MWCNT-BuGE and MWCNT-BeGE before applying the external stress. However, when the $1 \%$ bending load was applied, the G band frequency of MWCNT-BuGE (1596.2) and MWCNT-BeGE (1598.4) shifted to a higher wave number than that of $\mathrm{MWCNT}^{-N_{2}}$ (1594.6), indicating the effective stress transfer from the resin matrix to the surface sizing treated MWCNTs at their interfaces. The G band frequency of MWCNT-BeGE/epoxy nanocomposites was higher than that of MWCNT-BuGE/epoxy nanocomposites owing to the stronger interfacial interaction among the MWCNT-BeGE and the epoxy matrix.

Figure 10 shows relaxed conformations of the modeled MWCNT-BuGE/DGEBA/DDM (Figure 10a) and MWCNT-BeGE/DGEBA/DDM (Figure 10b) at $300 \mathrm{~K}$ using the MD simulation, and the evolution of interaction energy between each model chain and surface sizing treated MWCNTs during the relaxation process (Figure 10c). MWCNT-BeGE/DGEBA/DDM exhibited a higher average interaction energy $(-124.6 \mathrm{kcal} / \mathrm{mol})$ than that of the MWCNT-BuGE/DGEBA/DDM $(-159.3 \mathrm{kcal} / \mathrm{mol})$, which was in accordance with the results of the Raman spectral analysis above. The improved interfacial interaction can be contributed to the formation $\pi-\pi$ stacking between the aromatic rings in the MWCNT-BeGE backbone and the resin matrix $[9,38]$. 


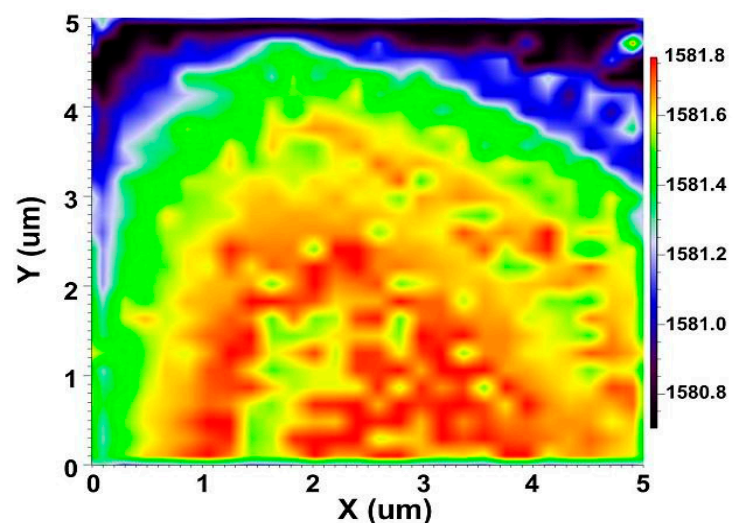

(a)

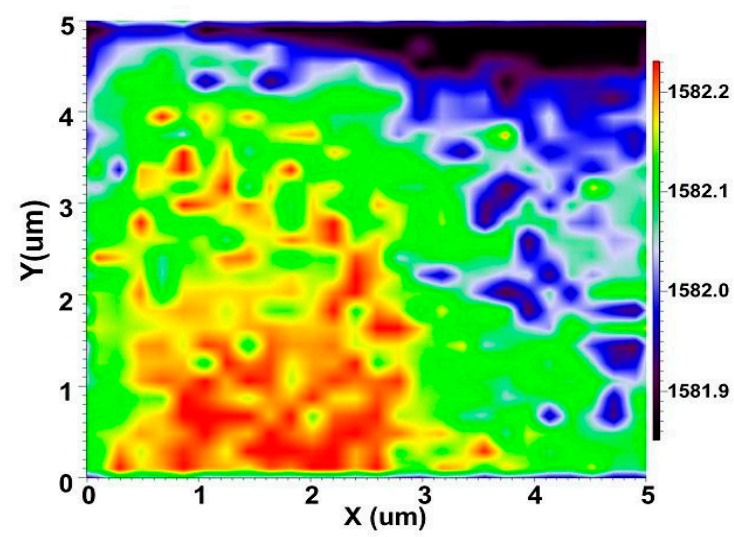

(c)

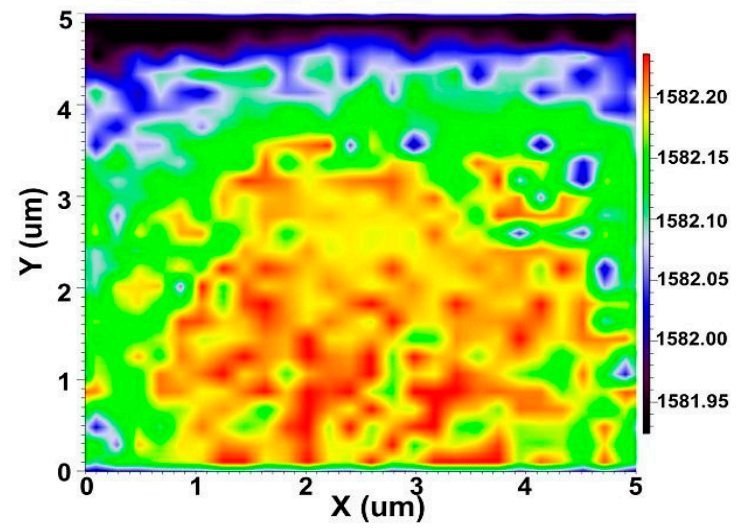

(e)

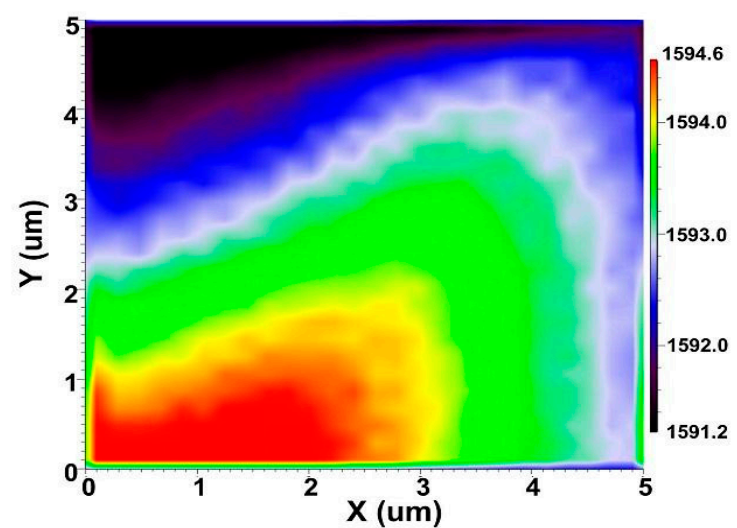

(b)

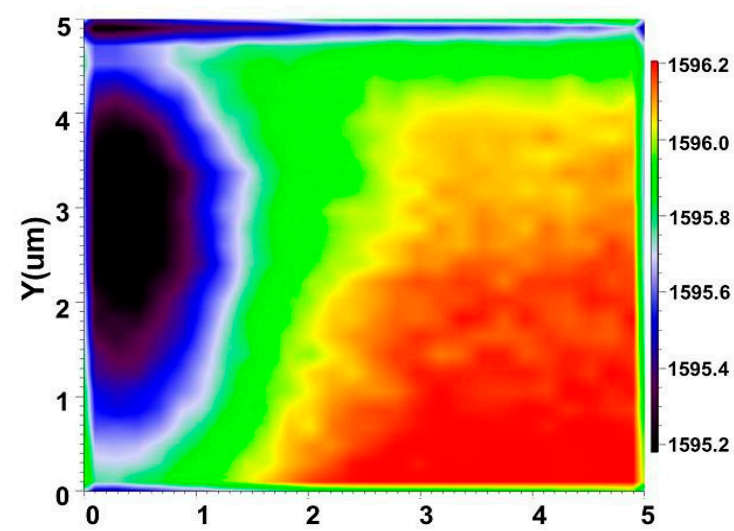

(d)

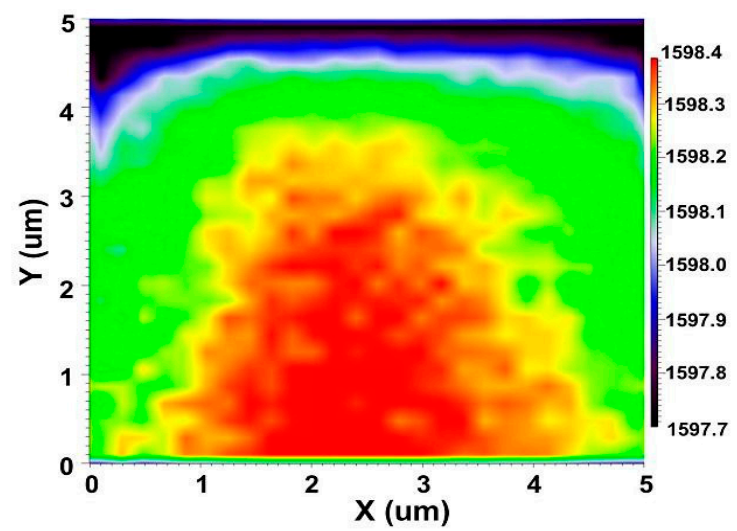

(f)

Figure 9. Raman mapping of $\mathrm{G}$ band of (a) MWCNT-NH $\mathrm{N}_{2}$ /epoxy nanocomposites, (b) MWCNT-NH $\mathrm{N}_{2}$ /epoxy nanocomposites with $1 \%$ bending load, (c) MWCNT-BuGE/epoxy nanocomposites, (d) MWCNT-BuGE/epoxy nanocomposites with 1\% bending load, (e) MWCNTBeGE/epoxy nanocomposites and (f) MWCNT-BeGE/epoxy nanocomposites with $1 \%$ bending load. Color-code: quantities related to MWCNTs are given in color, those of the epoxy matrix-in black. 


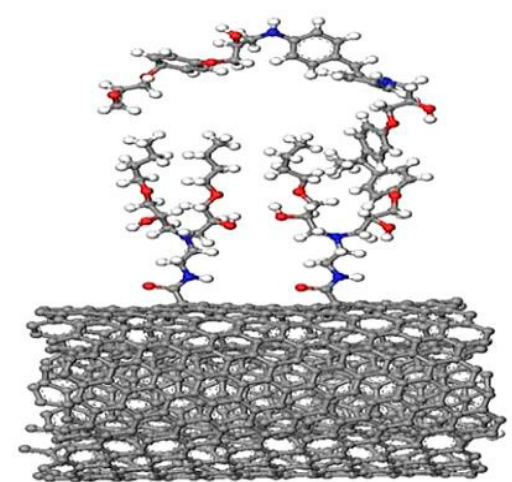

(a)

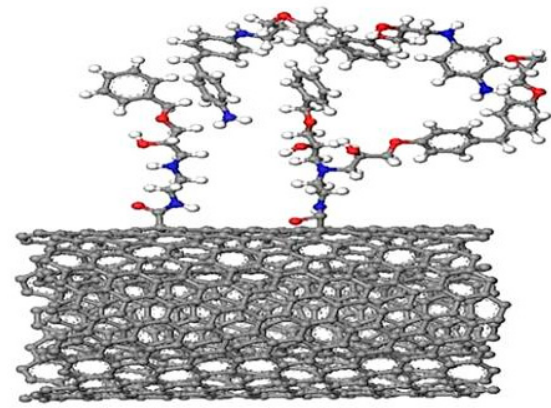

(b)

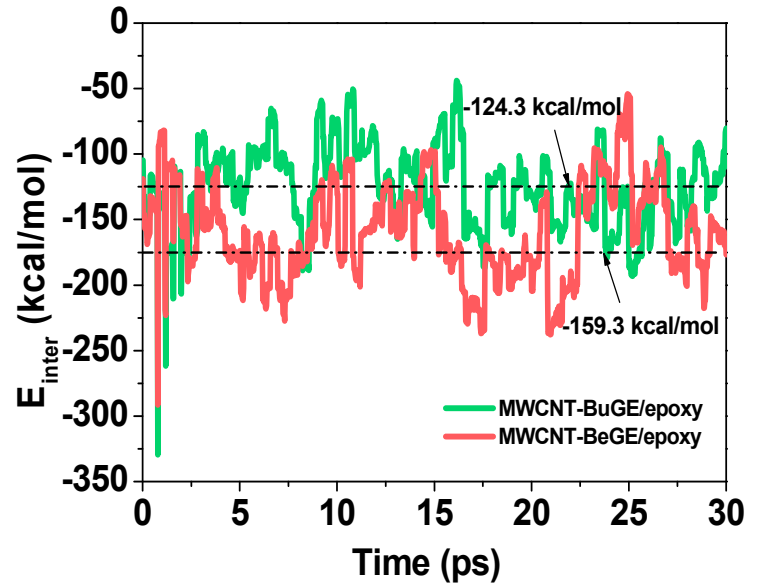

(c)

Figure 10. Schematics of interfacial microstructure of (a) MWCNT-BuGE/epoxy nanocomposites and (b) MWCNT-BeGE/epoxy nanocomposites; (c) the calculated intermolecular interaction energy of MWCNT-BuGE/epoxy and MWCNT-BeGE/epoxy during the relaxation process.

\subsection{Fracture Morphology and Mechanical Analysis of MWCNT/Epoxy Nanocomposite}

The fracture surfaces of neat resin and nanocomposites containing $\mathrm{MWCNT}_{\mathrm{NH}}, \mathrm{MWCNT}-\mathrm{BuGE}$ and MWCNT-BeGE were compared using SEM, as shown in Figure 11. Small MWCNT agglomerates were clearly seen from the sample containing $\mathrm{MWCNT}_{\mathrm{NH}}$ (Figure 11b, inset), while these agglomerates were almost absent in the sample containing MWCNT-BuGE (Figure 11c, inset) and MWCNT-BeGE (Figure 11d, inset). This result indicated that the surface sizing treated MWCNTs further improved the dispersion effect of $\mathrm{MWCNT}-\mathrm{NH}_{2}$ in the resin matrix. The surface sizing weakened the van der Waals' (vdW) force between the MWCNTs and enhanced the chemical compatibility with epoxy matrix, and thus led to the efficient debundling and satisfactory dispersion of MWCNTs in the nanocomposites.

The neat epoxy exhibited a smooth fracture surface, revealing the typical brittle fracture with poor resistance towards cracking or rupturing. By contrast, the fracture surfaces of the nanocomposites exhibited ridges, rivers and plastic deformation features. This was primarily because the presence of MWCNTs prevented cracks from propagating, increased the area of the fracture surface and provided a high resistance to fracture [39]. Compared with the MWCNT-NH${ }_{2}$, surface sizing treated MWCNTs showed a more evident reinforcement role in the resulting epoxy nanocomposites. Especially, the MWCNT-BeGE reinforced nanocomposites showed rather intricate and tortuous crack propagation, owing to the improved MWCNT dispersion, and interfacial energy between the MWCNT-BeGE and resin matrix promoted the load transfer effectively. 


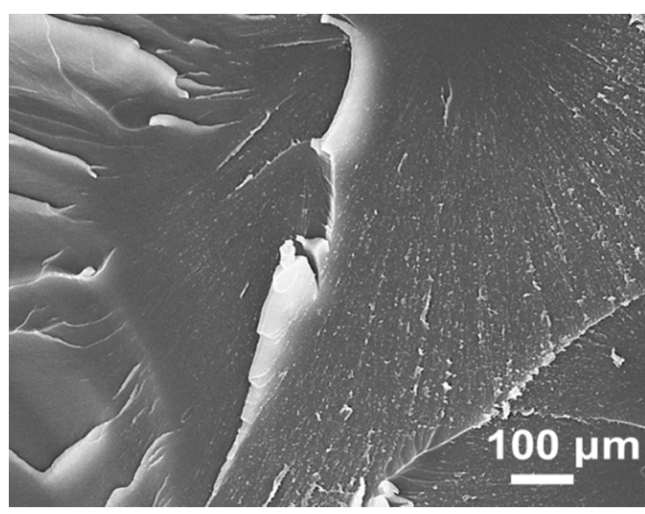

(a)

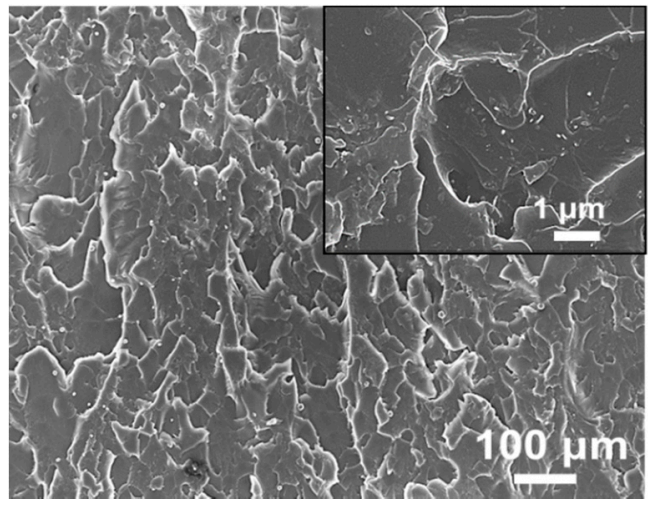

(c)

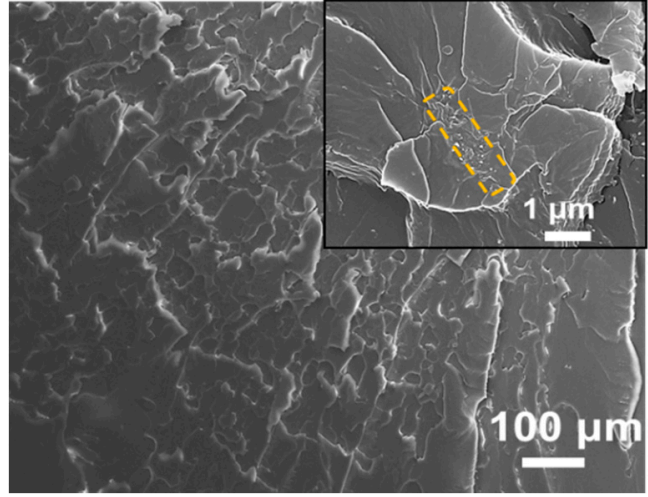

(b)

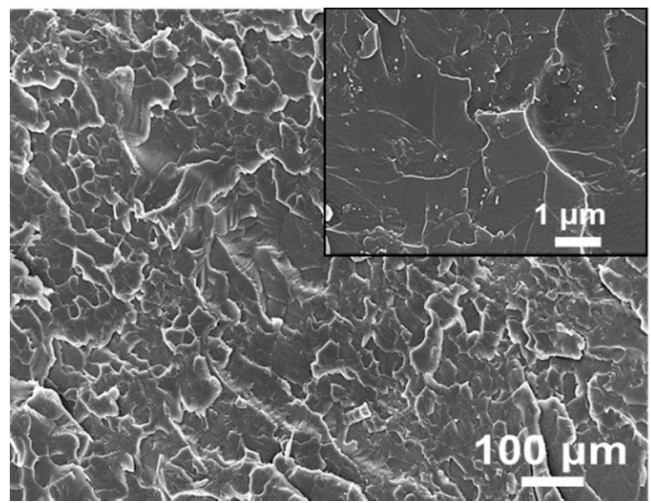

(d)

Figure 11. Scanning electron microscope (SEM) micrographs of fracture surface: (a) neat epoxy, (b) MWCNT-NH 2 /epoxy, (c) MWCNT-BuGE/epoxy and (d) MWCNT-BeGE/epoxy. Inset, high-magnification micrographs of dispersed MWCNTs in epoxy nanocomposites.

Flexural properties of MWCNT/epoxy resin composites were closely related to the MWCNT dispersion and interfacial interactions between the MWCNTs and resin matrix [25,39-41]. Figure 12a shows typical flexural stress-displacement curves of DGEBA/DDM reinforced by $\mathrm{MWCNT}-\mathrm{NH}_{2}$, MWCNT-BuGE and MWCNT-BeGE, and the average flexural strength and modulus were summarized in Figure 12b,c. Flexural strength and modulus of the neat resin were found to be $122 \mathrm{MPa}$ and $2.6 \mathrm{GPa}$, while these properties of MWCNT-NH 2 reinforced nanocomposites reached $135 \mathrm{MPa}$ and $3.2 \mathrm{GPa}$, with an increase of $11.0 \%$ and $23.1 \%$. By contrast, the surface sizing treated MWCNT/epoxy nanocomposites showed better flexural properties owing to the improved dispersion and wettability performance of epoxy-sizing MWCNTs compared with the MWCNT- $\mathrm{NH}_{2}$. The flexural strength and modulus of MWCNT-BeGE/epoxy nanocomposites can reach $150 \mathrm{MPa}$ and $3.6 \mathrm{GPa}$, with an increase of $22.9 \%$ and $37.8 \%$ compared with the neat epoxy, and 7.3\% and 7.7\% compared with MWCNT-BuGE/epoxy nanocomposites with the same MWCNT content, indicating that the surface sizing containing benzene rings offered a more efficient local load-transfer between MWCNTs and the epoxy matrix.

The comparison of flexural properties and their increases between this study and other researches for MWCNT/DGEBA systems is summarized in Table 2. Compared with control samples, increasing flexural strength from $12.1 \%$ to $26.7 \%$ and modulus from $17.6 \%$ to $21.7 \%$ of MWCNT/epoxy nanocomposites was observed in previous articles, which were inferior to synthetically reinforcing effect of surface sizing treated MWCNTs. 


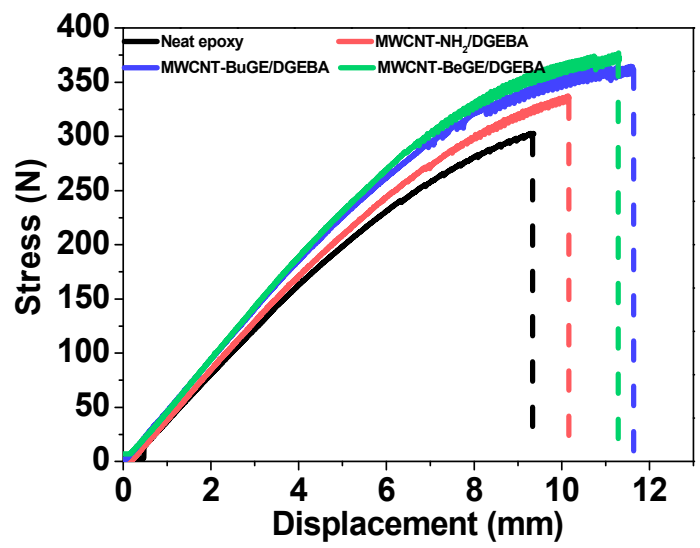

(a)

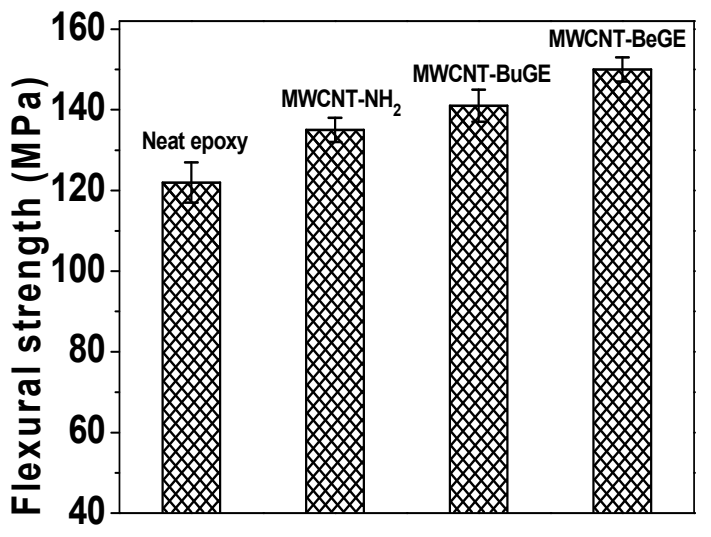

(b)

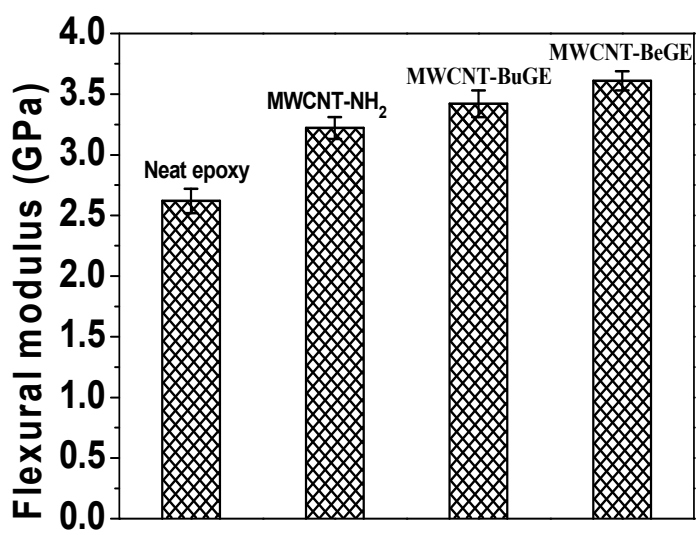

(c)

Figure 12. (a) Typical flexural stress-displacement curves, (b) the corresponding flexural strength and (c) flexural modulus of different nanocomposites.

Table 2. Comparison of flexural properties between this study and other researches for MWCNT/ DGEBA systems.

\begin{tabular}{|c|c|c|c|c|c|c|}
\hline \multirow{2}{*}{ CNT Type } & \multirow{2}{*}{ Content (wt.\%) } & \multicolumn{2}{|c|}{$\begin{array}{l}\text { Flexural Strength/Mpa } \\
\text { (Increase, \%) }\end{array}$} & \multicolumn{2}{|c|}{$\begin{array}{l}\text { Flexural Modulus/GPa } \\
\text { (Increase, \%) }\end{array}$} & \multirow[b]{2}{*}{ Reference } \\
\hline & & $\begin{array}{l}\text { Control } \\
\text { Sample }\end{array}$ & Composites & $\begin{array}{l}\text { Control } \\
\text { Sample }\end{array}$ & Composites & \\
\hline MWCNT-NH ${ }_{2}$ & 0.5 & 107 & $128(19.6 \%)$ & 2.92 & $3.51(20.2 \%)$ & [25] \\
\hline MWCNT-NH 2 & 0.5 & 90 & $102(13.3 \%)$ & 1.88 & $2.21(17.6 \%)$ & [39] \\
\hline MWCNT-NH 2 & 0.6 & 86 & $109(26.7 \%)$ & 2.21 & $2.69(21.7 \%)$ & [40] \\
\hline $\begin{array}{l}\text { MWCNT } \\
\text { derivatives }\end{array}$ & 1 & 109 & $122(12.1 \%)$ & - & 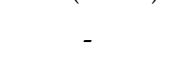 & [41] \\
\hline MWCNT-NH ${ }_{2}$ & 0.5 & 122 & $135(10.7 \%)$ & 2.62 & $3.22(22.9 \%)$ & This study \\
\hline MWCNT-BuGE & 0.5 & 122 & $141(15.6 \%)$ & 2.62 & $3.41(30.1 \%)$ & This study \\
\hline MWCNT-BeGE & 0.5 & 122 & $150(22.9 \%)$ & 2.62 & $3.61(37.8 \%)$ & This study \\
\hline
\end{tabular}

From the analysis above, the surface sizing treatment can effectively improve the wettability and dispersion of MWCNTs in the epoxy matrix. Moreover, a higher interfacial energy between the MWCNTs and epoxy matrix can improve the local load-transfer from weak resin matrix to the strong MWCNTs through the structural design of surface sizing. The surface sizing treatment is an effective process method to take full advantage of MWCNTs and epoxy resins, and has shown a good application prospect. 


\section{Conclusions}

In this study, through a ball-milling treatment with BuGE and BeGE, the MWCNT-NH 2 material was converted into two surface sizing treated MWCNTs: MWCNT-BuGE and MWCNT-BeGE. The surface sizing treatment effectively enhanced wettability, dispersibility and mechanical reinforcement of MWCNTs in the epoxy resin compared with MWCNT-NH $\mathrm{NH}_{2}$. The results of MD simulation and Raman spectroscopy indicated that the surface sizing containing benzene rings (MWCNT-BeGE) improved the interaction energy, and offered a more efficient local load-transfer between MWCNTs and the epoxy matrix, as observed by a higher G-band shift in Raman spectrum under bending loads than that of MWCNT-BuGE reinforced ones. As a consequence, the flexural strength and modulus of MWCNT-BeGE/epoxy nanocomposites reached $150 \mathrm{MPa}$ and 3.6 GPa, with an increase of $22.9 \%$ and $37.8 \%$ compared with the neat epoxy, and $7.3 \%$ and $7.7 \%$ compared with MWCNT-BuGE/epoxy nanocomposites with the same MWCNT content.

Author Contributions: Q.Z. and X.Z. prepared the setups for the experiments and measurements. Q.Z., G.S. and X.Y. designed the study and the project. Q.Z. and G.S. wrote the main text of the manuscript. All authors contributed to the discussion and reviewed the manuscript.

Funding: This research was funded by National Natural Science Foundation of China (No. U1664251).

Conflicts of Interest: The authors declare no conflict of interest.

\section{References}

1. Ricciardi, M.R.; Papa, I.; Langella, A.; Langella, T.; Lopresto, V.; Antonucci, V. Mechanical properties of glass fibre composites based on nitrile rubber toughened modified epoxy resin. Compos. Part B Eng. 2018, 139, 259-267. [CrossRef]

2. Chung, D.D.L. Processing-structure-property relationships of continuous carbon fiber polymer-matrix composites. Mater. Sci. Eng. R 2017, 113, 1-29. [CrossRef]

3. Jin, F.L.; Li, X.; Park, S.J. Synthesis and application of epoxy resins: A review. J. Ind. Eng. Chem. 2015, 29, 1-11. [CrossRef]

4. Domun, N.; Hadavinia, H.; Zhang, T.; Sainsbury, T.; Liaghat, G.H.; Vahid, S. Improving the fracture toughness and the strength of epoxy using nanomaterials-A review of the current status. Nanoscale 2015, 7, 10294-10329. [CrossRef] [PubMed]

5. Liu, S.; Chevali, V.S.; Xu, Z.G.; Hui, D.; Wang, H. A review of extending performance of epoxy resins using carbon nanomaterials. Compos. Part B Eng. 2018, 136, 197-214. [CrossRef]

6. Cui, M.J.; Ren, S.M.; Qiu, S.H.; Zhao, H.C.; Wang, L.P.; Xue, Q.J. Non-covalent functionalized multi-wall carbon nanotubes filled epoxy composites: Effect on corrosion protection and tribological performance. Surf. Coat. Technol. 2018, 340, 74-85. [CrossRef]

7. Quan, D.; Urdániz, J.L.; Ivanković, A. Enhancing mode-I and mode-II fracture toughness of epoxy and carbon fibre reinforced epoxy composites using multi-walled carbon nanotubes. Mater. Des. 2018, 143, 81-92. [CrossRef]

8. Garate, H.; Bianchi, M.; Pietrasanta, L.I.; Goyanes, S.; D’Accorso, N.B. High-energy dissipation performance in epoxy coatings by the synergistic effect of carbon nanotube/block copolymer conjugates. ACS Appl. Mater. Interfaces 2017, 9, 930-943. [CrossRef] [PubMed]

9. Chen, X.M.; Zhang, L.Y.; Zheng, M.; Park, C.; Wang, X.Q.; Ke, C.H. Quantitative nanomechanical characterization of the van der Waals interfaces between carbon nanotubes and epoxy. Carbon 2015, 82, 214-228. [CrossRef]

10. Owuor, P.S.; Yang, Y.; Kaji, T.; Koizumi, R.; Ozden, S.; Vajtai, R.; Lou, J.; Penev, E.S.; Yakobson, B.I.; Tiwary, C.S.; et al. Enhancing mechanical properties of nanocomposites using interconnected carbon nanotubes (iCNT) as reinforcement. Adv. Eng. Mater. 2017, 19, 1600499. [CrossRef]

11. Awad, S.A.; Fellows, C.M.; Mahini, S.S. Effects of accelerated weathering on the chemical, mechanical, thermal and morphological properties of an epoxy/multi-walled carbon nanotube composite. Polym. Test. 2018, 66, 70-77. [CrossRef] 
12. Li, Q.T.; Jiang, M.J.; Wu, G.; Chen, L.; Chen, S.C.; Cao, Y.X.; Wang, Y.Z. Photothermal conversion triggered precisely targeted healing of epoxy resin based on thermoreversible diels-alder network and amino-functionalized carbon nanotubes. ACS Appl. Mater. Interfaces 2017, 9, 20797-20807. [CrossRef] [PubMed]

13. Sydlik, S.A.; Lee, J.H.; Walish, J.J.; Thomas, E.L.; Swager, T.M. Epoxy functionalized multi-walled carbon nanotubes for improved adhesives. Carbon 2013, 59, 109-120. [CrossRef]

14. Stylianakis, M.M.; Mikroyannidis, J.A.; Kymakis, E. A facile, covalent modification of single-wall carbon nanotubes by thiophene for use in organic photovoltaic cells. Sol. Energy Mater. Sol. Cells 2010, 94, 267-274. [CrossRef]

15. Le, V.T.; Ngo, C.L.; Le, Q.T.; Ngo, T.T.; Nguyen, D.N.; Vu, M.T. Surface modification and functionalization of carbon nanotube with some organic compounds. Adv. Nat. Sci. Nanosci. Nanotechnol. 2013, 4, 035017. [CrossRef]

16. Sablok, K.; Bhalla, V.; Sharma, P.; Kausha, R.; Chaudhary, S.; Suri, C.R. Amine functionalized graphene oxide/CNT nanocomposite for ultrasensitive electrochemical detection of trinitrotoluene. J. Hazard. Mater. 2013, 248-249, 322-328. [CrossRef] [PubMed]

17. Mashhadzadeha, A.H.; Fereidoona, A.; Ahangari, M.G. Surface modification of carbon nanotubes using 3-aminopropyltriethoxysilane to improve mechanical properties of nanocomposite based polymer matrix: Experimental and Density functional theory study. Appl. Surf. Sci. 2017, 420, 167-179. [CrossRef]

18. Sharma, K.; Kaushalyayan, K.S.; Shukla, M. Pull-out simulations of interfacial properties of amine functionalized multi-walled carbon nanotube epoxy composites. Comput. Mater. Sci. 2015, 99, 232-241. [CrossRef]

19. Liu, Y.; Wilkinson, A. Rheological percolation behaviour and fracture properties of nanocomposites of MWCNTs and a highly crosslinked aerospace-grade epoxy resin system. Compos. Part A Appl. Sci. Manuf. 2018, 105, 97-107. [CrossRef]

20. Alam, A.; Wan, C.Y.; McNally, T. Surface amination of carbon nanoparticles for modification of epoxy resins: Plasma-treatment vs. wet-chemistry approach. Eur. Polym. J. 2017, 87, 422-448. [CrossRef]

21. Rezazadeh, V.; Pourhossaini, M.R.; Salimi, A. Effect of amine-functionalized dispersant on cure and electrical properties of carbon nanotube/epoxy nanocomposites. Prog. Org. Coat. 2017, 111, 389-394. [CrossRef]

22. Khare, K.S.; Khabaz, F.; Khare, R. Effect of carbon nanotube functionalization on mechanical and thermal properties of cross-linked epoxy-carbon nanotube nanocomposites: Role of strengthening the interfacial interactions. ACS Appl. Mater. Interfaces 2014, 6, 6098-6110. [CrossRef] [PubMed]

23. Cha, J.; Jun, G.H.; Park, J.K.; Kim, J.C.; Ryu, H.J.; Hong, S.H. Improvement of modulus, strength and fracture toughness of CNT/Epoxy nanocomposites through the functionalization of carbon nanotubes. Compos. Part B Eng. 2017, 129, 169-179. [CrossRef]

24. Lavorgna, M.; Romeo, V.; Martone, A.; Zarrelli, M.; Giordano, M.; Buonocore, G.G.; Qu, M.Z.; Fei, G.X.; Xia, H.S. Silanization and silica enrichment of multiwalled carbon nanotubes: Synergistic effects on the thermal-mechanical properties of epoxy nanocomposites. Eur. Polym. J. 2013, 49, 428-438. [CrossRef]

25. Ma, P.C.; Mo, S.Y.; Tang, B.Z.; Kim, J.K. Dispersion, interfacial interaction and re-agglomeration of functionalized carbon nanotubes in epoxy composites. Carbon 2012, 48, 1824-1834. [CrossRef]

26. Martinez-Rubi, Y.; Ashrafi, B.; Guan, J.; Kingston, C.; Johnston, A.; Simanrd, B.; Mirjalili, V.; Hubert, P.; Deng, L.B.; Young, R.J. Toughening of epoxy matrices with reduced single-walled carbon nanotubes. ACS Appl. Mater. Interfaces 2011, 3, 2309-2326. [CrossRef] [PubMed]

27. Jiao, W.W.; Cai, Y.M.; Liu, W.B.; Yang, F.; Jiang, L.; Jiao, W.C.; Wang, R.G. Preparation of carbon fiber unsaturated sizing agent for enhancing interfacial strength of carbon fiber/vinyl ester resin composite. Appl. Surf. Sci. 2018, 439, 88-95. [CrossRef]

28. Chang, C.M.; Liu, Y.L. Functionalization of multi-walled carbon nanotubes with non-reactive polymers through an ozone-mediated process for the preparation of a wide range of high performance polymer/carbon nanotube composites. Carbon 2010, 48, 1289-1297. [CrossRef]

29. Kim, S.W.; Kim, T.; Kim, Y.S.; Choi, H.S.; Lim, H.J.; Yang, S.J.; Park, C.R. Surface modifications for the effective dispersion of carbon nanotubes in solvents and polymers. Carbon 2012, 50, 3-33. [CrossRef]

30. Murugesan, S.; Myers, K.; Subramanian, V. Amino-functionalized and acid treated multi-walled carbon nanotubes as supports for electrochemical oxidation of formic acid. Appl. Catal. B Environ. 2011, 103, $266-274$. [CrossRef] 
31. Guo, J.; Zhang, Q.J.; Gao, L.; Zhong, W.H.; Sui, G.; Yang, X.P. Significantly improved electrical and interlaminar mechanical properties of carbon fiber laminated composites by using special carbon nanotube pre-dispersion mixture. Compos. Part A Appl. Sci. Manuf. 2017, 95, 294-303. [CrossRef]

32. Sharma, A.K.; Mahajan, A.; Bedi, R.K.; Kumar, S.; Debnath, A.K.; Aswal, D.K. Non-covalently anchored multi-walled carbon nanotubes with hexa-decafluorinated zinc phthalocyanine as ppb level chemiresistive chlorine sensor. Appl. Surf. Sci. 2018, 427, 202-209. [CrossRef]

33. Bibi, S.; Yasin, T.; Nawaz, M.; Price, G.J. Comparative study of the modification of multi-wall carbon nanotubes by gamma irradiation and sonochemically assisted acid etching. Mater. Chem. Phys. 2018, 207, 23-29. [CrossRef]

34. Maleki, A.; Hamesadeghi, U.; Daraei, H.; Hayati, B.; Najafi, F.; McKay, G.; Rezaee, R. Amine functionalized multi-walled carbon nanotubes: Single and binary systems for high capacity dye removal. Chem. Eng. J. 2017, 313, 826-835. [CrossRef]

35. Kang, W.S.; Rhee, K.Y.; Park, S.J. Influence of surface energetics of graphene oxide on fracture toughness of epoxy nanocomposites. Compos. Part B Eng. 2017, 114, 175-183. [CrossRef]

36. Zhao, M.; Meng, L.H.; Ma, L.C.; Ma, L.N.; Yang, X.B.; Huang, Y.D.; Ryu, J.E.; Shankar, A.; Li, T.X.; Yan, C.; et al. Layer-by-layer grafting CNTs onto carbon fibers surface for enhancing the interfacial properties of epoxy resin composites. Compos. Sci. Technol. 2018, 154, 28-36. [CrossRef]

37. Wang, S.R.; Liang, R.; Wang, B.; Zhang, C. Load-transfer in functionalized carbon nanotubes/polymer composites. Chem. Phys. Lett. 2008, 457, 371-375. [CrossRef]

38. Yu, B.; Fu, S.; Wu, Z.Q.; Bai, H.W.; Ning, N.Y.; Fu, Q. Molecular dynamics simulations of orientation induced interfacial enhancement between single walled carbon nanotube and aromatic polymers chains. Compos. Part A Appl. Sci. Manuf. 2015, 73, 155-165. [CrossRef]

39. Qu, Z.H.; Wang, G.J. A comparative study on the properties of the different amino-functionalized multiwall carbon nanotubes reinforced epoxy resin composites. J. Appl. Polym. Sci. 2012, 124, 403-408.

40. Yang, K.; Gu, M.Y.; Guo, Y.P.; Pan, X.F.; Mu, G.H. Effects of carbon nanotube functionalization on the mechanical and thermal properties of epoxy composites. Carbon 2009, 47, 1723-1737. [CrossRef]

41. Wu, F.; Zheng, Y.P.; Qu, P.; Wang, N.; Chen, L.X. A liquid-like multiwalled carbon nanotube derivative and its epoxy nanocomposites. J. Appl. Polym. Sci. 2013, 130, 2217-2224. [CrossRef]

(C) 2018 by the authors. Licensee MDPI, Basel, Switzerland. This article is an open access article distributed under the terms and conditions of the Creative Commons Attribution (CC BY) license (http:/ / creativecommons.org/licenses/by/4.0/). 